\title{
A Mathematical Model for Determining Job Rotation Strategy Considering Mental and Physical Fatique
}

\section{Yelda YENER and Gülin Feryal CAN* \\ Department of Industrial Engineering, Başkent University, Turkey}

*Corresponding author: Gülin Feryal CAN, Başkent University, Engineering Faculty, Industrial Engineering Department, Ankara, Turkey, Tel: 06810 +903122466666; Email: gfcan@baskent.edu.tr

\section{Research Article \\ Volume 2 Issue 5}

Received Date: September 11, 2018

Published Date: September 29, 2018

DOI: $10.23880 /$ eoij-16000181

\section{Abstract}

Job rotation is a type of work organization that provides the ability for doing more than one jobs for workers by directed those to different works at certain times of a working day. Mental and physical fatigue occurred on workers by high repetitive, needing attention and monotonous jobs are prevented with job rotation. By determining appropriate job rotation strategy, worker's productivity increase, company's production quantity and profitability are also increase. In this study, optimal job rotation strategy is attempted to determine by using mathematical model that aims the maximization of the production quantity in addition to reduce mental and physical fatigue. The mixed integer programming model is used for mathematical model. OWAS (Ovako Working Posture Analysis System) and NASA TLX (National Aeronautics and Space Administration Task Load Index) approaches are used to evaluate physical and mental exposure respectively. Moreover, performance changes among workers are also considered in the proposed model.

Keywords: Ergonomic Conditions; Job Rotation; Mathematical Modeling; NASA TLX; OWAS

\section{Introduction}

Job rotation is a process that includes structured interchange of workers between different jobs or different work stations. Job rotation requires rotating workers between different workstations or jobs at a certain time intervals. Variety of tasks, duties and workers' skills are increased by the help of the job rotation. It has many great benefits for the workers and work places. Reduced physical exposure because of the physical demands of the jobs or tasks is emerged by the job rotation. Physiological stress, strain, and fatigue of muscle group used for one job are also decreased. At the same time, incidents and severity of occupational musculoskeletal disorders (OMSDs) decrease. Work process efficiency is increased with job rotation implementation. It supports increasing job assignment flexibility over time. Boredom and complacency is declined because of the possibility for working in different jobs. This affects the productivity of the manufacturing process and the quality of the products. Finally, absenteeism and turnover of the workers reduce.

It is a powerful control measure for the high risk jobs or tasks. However, job rotation doesn't eliminate the ergonomic risk factors in a desirable level. When a job rotation strategy is applied, there have still been ergonomic problems related to jobs or tasks. For this reason considering ergonomic conditions of the jobs or tasks, suitable job rotation strategy should be structured. 


\section{Ergonomics International Journal}

Managers have much greater flexibility when workers are trained to perform a variety of jobs. For the effective design of the job rotation strategy each job is evaluated considering job factors as muscle groups used, forces, postures, repetition, sustained exertions, tools utilized, and skill / training requirements etc. by the expert team. This expert team should include consult management, supervisors, group leaders, safety and ergonomics team members and employees.

There is limited number of studies related to structuring suitable job rotation strategy. Seçkiner and Kurt [1] showed the effectiveness of ant colony optimization for solving the job rotation scheduling problem. Aryanezhad et al. [2] developed an approach dealing with safe skill-based job rotation scheduling (SSJRS). Tharmmaphornphilas [3] proposed a job rotation scheduling method by using administrative controls and a computer programming model to reduce the likelihood of worker hearing loss. Otto and Scholl [4] presented the ways to structure effective job rotation schedules that consider balancing ergonomic risks among workers. Song et al. [5] presented a job rotation algorithm that minimizes musculoskeletal disorders with decreasing the overall workload. Moussavi, et al. [6] developed a rotation program that considers ergonomic risks for a planning period. Yoon, et al. [7] proposed a job rotation schedule by using a mathematical model that reduces cumulative workload of the same body region. As seen from the literature, most of the ergonomic factors except mental workload have been considered for establishing job rotation strategy. However, mental workload is a key point in for higher levels of comfort, satisfaction, efficiency, and safety in the workplace and workers' productivity. Besides, performance changes of workers, posture and load related risk factors have not been evaluated in the job rotation schedules in the context of the literature.

Xie and Salvendy [8] advanced a practical model to predict mental workload occurring in single and multitasks production process. Jung and Jung [9] proposed a workload estimation model by performing AHP and fuzzy logic to determine workload of workers in humanmachine systems. Dağdeviren, et al. 10] developed a total workload estimation model via using Analytic Network Process (ANP). Corominas, et al. [11] aimed to balance assembly line for motorcycles production due to the change of production in spring and summer. They preferred to use 0-1 integer programming model. Wongwien and Nanthavanij [12] aimed to solve ergonomic workload scheduling problem considering daily noise exposure threshold. Kara VD [13] handled an assembly line balancing problem including resource and ergonomic constraints as psychological, physical exposure, worker skills, the necessity of using more than one workers condition of the equipment used, risk level of working postures. Akyol and Baykasoğlu [14] suggested a new worker assignment and balancing model regarding ergonomic risks. The proposed model consists of multiple rule-based constructive heuristic approaches. To evaluate ergonomic risks in their study, Occupational Repetitive Actions (OCRA) index was implemented with the support of goal programming. Otto and Battaia $[15,16]$ reviewed current optimization approaches including assembly line balancing and job rotation. Comper, et al. [17] evaluated the effectiveness of job rotation implementing for reducing lost working hours due to musculoskeletal disorders. Wongwien and Nanthavanij [18] stated in their studies that job rotation helps to increase workers' efficiencies appointing the right workers at the right times in each period. Wongwien and Nanthavanij [18] developed multiple goal ergonomic worker scheduling models. Their aims are three-fold as minimizing the numbers of workers for job rotation, maximizing the total efficiency, minimizing worker-tasks changes. In this context, they used integer programming model and heuristic approach. Dolgui, et al. (2018) [19] suggested a complex integer programming model that aims to minimize the maximum number of workers, exceeding cycle time of line and possible numbers of workers for each task. Fini, et al. (2018) [20] proposed a new approach based on task assignment in teams in the construction industry to balance workload considering the skill levels, experience levels, learning rates, fatigue rates of different workers.

In this study a proactive optimal job rotation strategy is proposed by considering physical exposure and never studied mental work load of the workers. A zero-one programming model that aims the maximization of the production quantity in addition to reduce mental and physical fatigue is structured for finding optimal strategy. OWAS (Ovako Working Posture Analysis System) and NASA TLX (National Aeronautics and Space Administration Task Load Index) approaches are used to evaluate physical and mental exposure respectively. Moreover, performance changes among workers are also considered in the proposed model.

\section{Method}

\section{Ovako Working Posture Analyzing System (OWAS)}

OWAS is developed by Ovako Oy [21]. It is a practical method for evaluating working postures and determining the risk level of these postures based on work sampling. 


\section{Ergonomics International Journal}

OWAS evaluates the working postures of three body parts as back, arms and legs. Three posture categories for arm, four posture categories for back and seven posture categories for legs are consisted in OWAS. Besides, the weight of the load handled is analyzed by dividing in to three categories. These posture categories related to the body parts are shown in Figure 1.Coding system of OWAS is given in Figure 1.

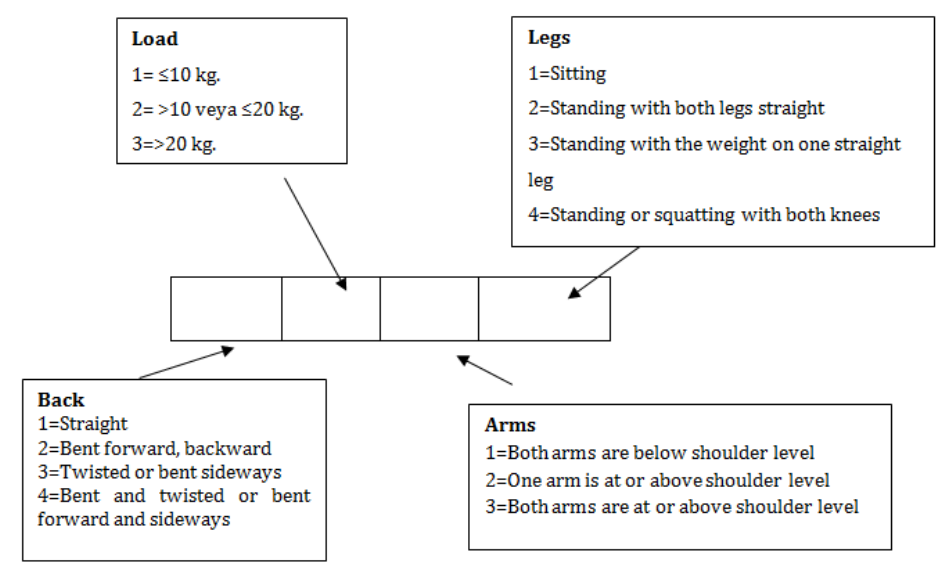

Figure 1: Working postures categorized in OWAS method [22].

OWAS aims to determine the time spent for each work and the frequency of postures in a certain time range [23].
Acceptable percentage of the each code for each body part is represented in Table 1.

\begin{tabular}{|c|c|c|c|c|c|c|c|c|}
\hline \begin{tabular}{|c|} 
Trunk \\
Posture \\
Code \\
\end{tabular} & Time (\%) & Risk Level & \begin{tabular}{|c|} 
Arm \\
Posture \\
Code \\
\end{tabular} & $\begin{array}{l}\text { Time } \\
(\%)\end{array}$ & Risk Level & \begin{tabular}{|c|} 
Lower Body \\
Posture \\
Code
\end{tabular} & Time (\%) & Risk Level \\
\hline \begin{tabular}{|l|}
1 \\
\end{tabular} & $\% 100$ & Acceptable & 1 & $\% 100$ & Acceptable & \multirow[b]{2}{*}{1} & $\% 90$ & Acceptable \\
\hline \multirow[b]{3}{*}{2} & $\% 30$ & Acceptable & \multirow[b]{3}{*}{2} & $\% 30$ & Acceptable & & $\% 90-\% 100$ & $\begin{array}{l}\text { Somewhat } \\
\text { dangerous }\end{array}$ \\
\hline & $\% 30-\% 80$ & $\begin{array}{l}\text { Somewhat } \\
\text { dangerous }\end{array}$ & & $\% 30-\% 80$ & $\begin{array}{l}\text { Somewhat } \\
\text { dangerous }\end{array}$ & \multirow[b]{2}{*}{2} & $\% 80$ & Acceptable \\
\hline & $\% 80-\% 100$ & Very dangerous & & $\% 80-\% 100$ & Very dangerous & & $\% 80$ - \%100 & $\begin{array}{l}\text { Somewhat } \\
\text { dangerous }\end{array}$ \\
\hline \multirow{3}{*}{3} & $\% 20$ & Acceptable & \multirow{3}{*}{3} & $\% 20$ & Acceptable & \multirow{3}{*}{3} & $\% 30$ & Acceptable \\
\hline & $\% 20-\% 50$ & $\begin{array}{l}\text { Somewhat } \\
\text { dangerous }\end{array}$ & & $\% 20-\% 70$ & $\begin{array}{l}\text { Somewhat } \\
\text { dangerous }\end{array}$ & & $\% 30-\% 80$ & $\begin{array}{l}\text { Somewhat } \\
\text { dangerous }\end{array}$ \\
\hline & $\% 50-\% 100$ & Very dangerous & & $\% 70-\% 100$ & Very dangerous & & $\% 80-\% 100$ & Very dangerous \\
\hline \multirow{9}{*}{4} & $\% 5$ & Acceptable & & & & \multirow{4}{*}{$4-5$} & $\% 5$ & Acceptable \\
\hline & $\% 5-\% 30$ & $\begin{array}{l}\text { Somewhat } \\
\text { dangerous }\end{array}$ & & & & & $\% 5-\% 30$ & $\begin{array}{l}\text { Somewhat } \\
\text { dangerous }\end{array}$ \\
\hline & $\% 30$ - \%70 & Very dangerous & & & & & $\% 30-\% 70$ & Very dangerous \\
\hline & $\% 70-\% 100$ & Too dangerous & & & & & $\% 70-\% 100$ & \begin{tabular}{|l} 
Too dangerous \\
\end{tabular} \\
\hline & & & & & & \multirow{3}{*}{6} & $\% 20$ & Acceptable \\
\hline & & & & & & & $\% 20$ - \%50 & $\begin{array}{l}\text { Somewhat } \\
\text { dangerous }\end{array}$ \\
\hline & & & & & & & $\% 50-\% 100$ & Very dangerous \\
\hline & & & & & & \multirow[b]{2}{*}{7} & $\% 880$ & Acceptable \\
\hline & & & & & & & $\% 80$ - \%100 & $\begin{array}{l}\text { Somewhat } \\
\text { dangerous }\end{array}$ \\
\hline
\end{tabular}

Posture combinations are evaluated in terms of risk level according to the 4 risk categories.

Table 1: Acceptable percentage of the each body part. 


\section{Ergonomics International Journal}

\begin{tabular}{|c|c|}
\hline Risk category & Definition \\
\hline Category 1 & $\begin{array}{c}\text { Working postures don't have any harmful effect on musculoskeletal system. There is no need of } \\
\text { ergonomic regulations for these postures. }\end{array}$ \\
\hline Category 2 & $\begin{array}{r}\text { There are some harmful effects of working postures on the musculoskeletal system. Necessary } \\
\text { ergonomic regulations should be planned in the future. }\end{array}$ \\
\hline Category 3 & $\begin{array}{r}\text { Working postures have some harmful effects on the musculoskeletal system. Necessary ergonomic } \\
\text { regulations should be planned as soon as possible. }\end{array}$ \\
\hline Category 4 & $\begin{array}{r}\text { Working postures have very harmful effects on the musculoskeletal system. Necessary ergonomic } \\
\text { regulations should be implemented urgently. }\end{array}$ \\
\hline
\end{tabular}

OWAS is used for posture evaluation in many studies in the literature [24-28].

Table 2: Risk categories in OWAS.

\section{National Aeronautics and Space Administration Task Load Index (NASA TLX)}

NASA TLX grades the mental workload considering six dimensions as physical and mental demands, temporal demand and performance level, effort and frustration levels. It is a reliable and accurate analysis tool and its scale validity and reliability were verified in many studies. The physical demand is the amount of physical activity necessary for the completion of the work. The mental demand means that the mental and sensory activity required during the completion of the work. Temporal demand represents the amount of working pace and time stress caused by the completion of the work. The performance level demonstrates the degree of success which the employee feels him/her in the completion of the job on time. The effort dimension is the amount of physical and mental exertion for the achievement of the performance level specified. The frustration level shows the level of insecurity, disenchantment and anger during the completion of the work.

NASA TLX scale consists of two parts. Each of six mental workload dimensions is graded between 0-100 with taking into consideration of work done in the first part by worker. The second part includes the pair wise comparison to determine the dominance of the dimension over the others. 15 double comparisons are performed for six different dimensions totally. Considering the comparisons and using the grades obtained in the first part, the workload values can be computed for each dimension. Mental workload point is obtained by the summation of the six dimensions workload points as given in Eq. (1). The mental workload varies between 0 and 100. NASA TLX Rating Scale Definitions are given in Table 3.

$$
\text { Mental Workload }=M D \times W_{M D}+P D \times W_{P D}+T D \times W_{T D}+F L \times W_{F L}+E L \times W_{E L}+P L \times W_{P L}
$$

\begin{tabular}{|c|c|c|}
\hline Title & Endpoints & Descriptions \\
\hline $\begin{array}{l}\text { Mental } \\
\text { Demand }\end{array}$ & Low/High & $\begin{array}{l}\text { How much mental and perceptual activity was required (e.g., thinking, deciding, calculating, } \\
\text { remebering, looking, searching etc.)? Was the task easy or demanding, simple or complex, } \\
\text { exacting or forgiving? }\end{array}$ \\
\hline $\begin{array}{l}\text { Physical } \\
\text { Demand }\end{array}$ & Low/High & $\begin{array}{c}\text { How much physical activity was required (e.g., pushing, pulling, turning, controlling, } \\
\text { activating, etc.)? Was the task easy or demanding, slow or brisk, slack or strenous, restful } \\
\text { or laborious? }\end{array}$ \\
\hline $\begin{array}{l}\text { Temporal } \\
\text { Demand }\end{array}$ & Low/High & $\begin{array}{l}\text { How much time pressure did you feel due to the rate or pace at which the tasks or task } \\
\text { elements occured? Was the pace slow and leisurely or rapid and frantic? }\end{array}$ \\
\hline Performance & Good/Poor & $\begin{array}{l}\text { How successful do you think you were in accomplishing the goals of the task set by the } \\
\text { experimenter (or yourself)? How satisfied were you with your performance in } \\
\text { accomplishing these goals? }\end{array}$ \\
\hline Effort & Low/High & $\begin{array}{c}\text { How hard did you have to work (mentally and physically) to accomplish your level of } \\
\text { performance? }\end{array}$ \\
\hline $\begin{array}{c}\text { Frustration } \\
\text { Level }\end{array}$ & Low/High & $\begin{array}{l}\text { How insecure, discouraged, irritated, stressed and annoyed versus secure, gratified, } \\
\text { content, relaxed and complacent did you feel during the task? }\end{array}$ \\
\hline
\end{tabular}

Table 3: NASA TLX Rating Scale Definitions.

NASA TLX has been used to determine subjective workload in many studie [29-31]. 


\section{Ergonomics International Journal}

\section{The Proposed Approach}

The proposed approach consists of three main stage as analyzing working postures with OWAS, obtaining mental workload scores with NASA TLX and determining optimal job rotation strategy with zero-one integer programming. Steps of the proposed approach are given below.

- Step 1: Analyze working postures of workers by using OWAS

Working postures of each worker are evaluated according to OWAS procedure as stated in Section 2.1.

- Step 2: Compute mental workload of each worker by using NASA TLX

Mental workloads of each worker are computed according to NASA TLX procedure as represented in Section 2.2.

- Step 3: Determine the optimal job rotation strategy by using zero-one integer programming

This step aims to introduce how it is possible to increase the production quantity by developing proper job rotation within in the work shift and, at the same time to reduce the risk of mental and physical fatigue of the workers. Therefore, optimal job rotation strategy that maximizes production quantity and reduces mental and physical fatigue is determined by using zero-one integer programming. In this context, notations used in zero-one integer programming are given below [32,33].

It is assumed that the firm works only one shift. This work shift consists of $d$ working time slots. The total duration of work shift $D_{s}$, excluding the planned breaks, is equal to the sum of the $d$ working time slot durations $D_{t}$. Workers are divided into $l$ categories. The workerm $(m=$ $1, \ldots, l)$ perform each specific job $k$ with a predetermined performance rate. Task completion time per unit $t_{m k}$ is used to measure the performance of the workerm in the manual repetitive task $k$ and it changes depending on performance rate of the worker. Therefore, each worker $m$ can be characterized by his performance rate. The completion time $t_{m k}$ can be expressed as a function of the workers performance rate $t_{m k}$ is computed as in Eq.(2).

$$
t_{m k}=t_{k} / c_{m k}
$$

Where $t_{k}$, is the task completion time and $c_{m k}$, is the performance rate coefficient $\left(c_{m k}>0\right)$ of the worker $m$ for the given task $k . t_{m k}$ is a decreasing function of $t_{k}$.
Considering ergonomic conditions, for each workerm, OWAS and NASA TLX values must be in acceptable levels to increase production quantity. According to definitions given above, zero-one integer programming model is presented as follows.

$$
\text { 0.F. }=\max \sum_{m-1}^{1} \sum_{k-1}^{n} \sum_{t-1}^{h} y_{m k t} x_{m k t}
$$

$$
\begin{aligned}
& \text { s.t. } \\
& \sum_{k-1}^{n} y_{m k t}=1, \forall m, t \text { (4) } \\
& \sum_{m-1}^{1} y_{m k t}=1, \forall k, t \text { (5) } \\
& 1 \leq x_{m k t} \leq D_{t} / t_{m k}, \forall m, k, t \text { (6) } \\
& x_{k}^{\min } \leq x_{k} \leq x_{k}^{\max }, \forall k \text { (7) } \\
& \left(O W A S_{1, p}\right)_{m} \leq\left(O W A S_{1, p}^{a c c}\right)_{l}, \forall m, p \text { (8) } \\
& \left(O W A S_{2, r}\right)_{m} \leq\left(O W A S_{2, r}^{a c c}\right)_{m}, \forall m, r(9) \\
& \left(O W A S_{3, s}\right)_{m} \leq\left(O W A S_{3, s}^{a c c}\right)_{m}, \forall m, s \quad(10) \\
& \left(O W A S_{4, v}\right)_{m} \leq\left(O W A S_{4, v}^{a c c}\right)_{m}, \forall m, v \text { (11) } \\
& N T L X_{m} \leq N T L X_{m}^{\max }, \forall m(12) \\
& y_{m k t} \in\{0,1\}(13)
\end{aligned}
$$

The proposed model is an integer nonlinear programming model. Among the decision variables, $y_{m k t}$ are defined as binary. It is assumed that it has a unique value when worker $m$ is assigned to work $k$ in the period $t$, and zero otherwise.

The objective function given with Eq. (3) defines the maximization of the production quantity performed by all workers and it is denoted as $x_{m k t}$. Constraints given with Eq. (4) and (5) provide that each worker $(m)$ is assigned a work $(k)$ provided that $l$ is equal to $n$. Constraint given with Eq. (6) shows that the maximum production quantity of a work $(k)$ is based on the performance rate of the worker $(m)$ assigned tothis work. Constraint given with Eq. (7) limits the quantity of production because of the production quantity that can be accepted in each shift. Constraints given with Eq. (8-11) defines an acceptable risk values $O W A S^{a c c}$ for each posture for each worker. This acceptable value is obtained by OWAS method. Each posture is separated into different categories as shown in Section 2.1. and the model is constructed based on this categorization. To integrate OWAS method with the proposed model, first index is used for symbolizing posture code and second index is used for identifying the categories of each posture code respectively. Technical coefficients related to Constraints given with Eq. (8-11) are computed as in Eq. (14). Constraint given with Eq. 


\section{Ergonomics International Journal}

(12) defines acceptable upper limitNTLX ${ }^{a c c}$ for mental fatigue for each worker. Technical coefficients related to Constraint given with Eq. (12) are computed as in Eq.
(15). Constraint given with Eq. (13) describes that decision variables $y_{m k t}$ are binary.

$$
\begin{gathered}
\left(\operatorname{OWAS}_{(1,2,3,4),(p, r, s, v)}\right)_{m}=\sum_{k=1}^{n} \frac{y_{m k t} f_{m}}{D_{t}}, \forall t, f_{m}: \text { time of current posture for each workers } \\
\quad N T L X_{m}=y_{m k t} * A_{m k t}, \forall m, k, t, A_{m k t}: \text { NASATLX score for each workers }
\end{gathered}
$$

\section{Application}

This study is conducted in a dishwasher production factory in Ankara. All workers are done their work in standing posture. Many workers on the dishwasher assembly line take breaks and medical reports due to musculoskeletal disorders. Working postures related to body insertion to the dishwasher, attachment of the gasket to the chamber, fitting sealing sponge, detergent dispenser assembly, drum fitting jobs are analyzed with OWAS. Workers have been performed their jobs in the dishwasher assembly for eight hour shift (08:00 am-17:00 $\mathrm{pm})$. Three breaks are planned in each shift. Therefore, each work shift is divided into four working time slots. Production time slots and breaks are depicted in Table4. The actual working time of one work shift is 450 minutes (two 15 minutes breaks and one 60 minutes lunch break).

\begin{tabular}{|c|c|c|c|c|c|c|}
\hline \multicolumn{7}{|c|}{ 08:00-17:00 } \\
\hline 08:00-10:00 & $\mathbf{1 0 : 0 0 - 1 0 : 1 5}$ & $\mathbf{1 0 : 1 5 - 1 2 : 0 0}$ & $\mathbf{1 2 : 0 0 - 1 3 : 0 0}$ & $\mathbf{1 3 : 0 0 - 1 5 : 0 0}$ & $\mathbf{1 5 : 0 0 - 1 5 : 1 5}$ & $\mathbf{1 5 : 1 5 - 1 7 : 0 0}$ \\
\hline working & break & working & break & working & break & working \\
\hline $120 \mathrm{~min}$ & $15 \mathrm{~min}$ & $105 \mathrm{~min}$ & $60 \mathrm{~min}$ & $120 \mathrm{~min}$ & $15 \mathrm{~min}$ & $105 \mathrm{~min}$ \\
\hline
\end{tabular}

Table 4: Production and break times.

Predetermined five jobs are performed in independent parallel manual assembly work stations. Body insertion to the dishwasher job is done in workstation 1 , attachment of the gasket to the chamber job is done in workstation 2 , fitting sealing sponge is performed in workstation 3, detergent dispenser assembly job is performed in workstation 4 and, drum fitting job is performed in workstation 5. One operator is working in each station. Each worker has ability to perform these five different jobs. Besides, each worker has ability to perform these five different jobs with different performance level. In the context of the study 4 skill levels have been determined as. To obtain the maximum production quantity in each station, the most skilled worker/s should assign to each station.

- Step 1: Analyze working postures of workers by using OWAS
For utilizing OWAS method 5workers are recorded for 30 minutes [34]. 30 minutes include 50 job cycles for body insertion to the dishwasher, 40 cycles for attachment of the gasket to the chamber, 35 cycles for fitting sealing sponge, 30 cycles for detergent dispenser assembly, 52 cycles for drum fitting and these numbers are found to be enough to represent the whole job. The postures represented in each task are recorded with video. Vide record is stopped every five second to increase the observational sensitivity [23] and 9000 posture images is coded according to OWAS method for each worker. WinO was package software is used for analyzing postures. 1800 working postures are gathered and the risk categories of these postures are shown in

\begin{tabular}{|c|c|c|c|c|c|c|c|c|c|c|c|c|c|c|c|c|c|}
\hline \multirow{3}{*}{ Workers } & \multicolumn{17}{|c|}{ Posture durations of first workers for different body parts (min) } \\
\hline & \multicolumn{4}{|c|}{ Trunk Posture } & \multicolumn{3}{|c|}{ Arm Posture } & \multicolumn{7}{|c|}{ Lower Body Posture } & \multicolumn{3}{|c|}{ Load } \\
\hline & 1 & 2 & 3 & 4 & 1 & 2 & 3 & 1 & 2 & 3 & 4 & 5 & 6 & 7 & 1 & 2 & 3 \\
\hline 1. work & 16 & 11 & 7 & 3 & 16 & 13 & 10 & 16 & 7 & 6 & 6 & 4 & 3 & 6 & 10 & 5 & 3 \\
\hline 2. work & 13 & 13 & 6 & 4 & 19 & 12 & 8 & 13 & 11 & 6 & 3 & 6 & 3 & 6 & 15 & 7 & 1.5 \\
\hline 3. work & 19 & 13 & 3 & 1.5 & 13 & 16 & 10 & 19 & 6 & 10 & 6 & 1.5 & 1.5 & 3 & 17 & 9 & 5 \\
\hline 4. work & 21 & 15 & 3 & 3 & 21 & 11 & 7 & 16 & 13 & 1.5 & 1.5 & 3 & 1.5 & 4 & 10 & 7 & 2 \\
\hline 5.work & 26 & 8 & 4 & 1 & 23 & 9.5 & 3 & 13 & 11 & 3 & 4 & 1.5 & 0.6 & 13 & 11 & 5 & 3 \\
\hline
\end{tabular}
Table 5 .

Table 5: Posture values for each work. 


\section{Ergonomics International Journal}

- Step 2: Compute mental workload of each worker by using NASA TLX

NASA TLX scale is used for measuring the mental workload of the assembly line worker. The scale was applied each five predetermined job rotation period. The scale was given as a written document to the workers after the definitions related to NASA TLX is done to them in a face to face manner. The scale was distributed to the workers at the same time; at the end of the rotation period.

\begin{tabular}{|c|c|c|c|c|c|c|}
\hline \multicolumn{7}{|c|}{ NASA TLX Points } \\
\hline $\boldsymbol{k}$ & $\boldsymbol{t}$ & 1.worker & 2.worker & 3.worker & 4.worker & 5.worker \\
\hline \multirow{4}{*}{1} & 1 & 44.67 & 44.67 & 39.67 & 48.33 & 43.33 \\
\cline { 2 - 7 } & 2 & 49.63 & 42.33 & 58.67 & 50 & 45 \\
\cline { 2 - 7 } & 3 & 50 & 47.33 & 39.67 & 49.67 & 51.67 \\
\cline { 2 - 7 } & 4 & 40.33 & 44.67 & 39.67 & 51.33 & 48 \\
\hline
\end{tabular}

Table 6: NASA TLX Points of workers for the first period for 5 different tasks.

- Step 3: Determine the optimal job rotation strategy by using zero-one integer programming

In this study the different performance rate of workers are considered. This can differentiate production quantity due to changing production time. In Table 7, an optimal solution of job rotation problem is shown based on production quantity. Moreover, worker assignments to five jobs are seen from Table 6. As an example, first worker is assigned to the first and fifth job sat the first and fourth periods and at the first and third periods, respectively. The same interpretation can be made for the others. According to the results of the proposed model, it is seen that a worker is assigned to each work. Similarly, it is seen that a work is assigned to each worker $[35,36]$.

\begin{tabular}{|c|c|c|c|c|c|c|}
\hline \multirow{2}{*}{$m$} & \multirow{2}{*}{$\boldsymbol{k}$} & \multicolumn{4}{|c|}{$x_{m k t}$} & \multirow{2}{*}{$x_{k}$} \\
\hline & & $t=1$ & $t=2$ & $t=3$ & $t=4$ & \\
\hline \multirow{5}{*}{1} & 1 & & 263 & & 263 & \multirow{5}{*}{1142} \\
\hline & 2 & & & & & \\
\hline & 3 & & & & & \\
\hline & 4 & & & & & \\
\hline & 5 & 308 & & 308 & & \\
\hline \multirow{5}{*}{2} & 1 & & & & & \multirow{5}{*}{521} \\
\hline & 2 & & 140 & & & \\
\hline & 3 & 139 & & & 122 & \\
\hline & 4 & & & 120 & & \\
\hline & 5 & & & & & \\
\hline \multirow{5}{*}{3} & 1 & & & & & \multirow{5}{*}{455} \\
\hline & 2 & & & & 127 & \\
\hline & 3 & & 125 & & & \\
\hline & 4 & 108 & 95 & & & \\
\hline & 5 & & & & & \\
\hline \multirow{5}{*}{4} & 1 & 250 & & 250 & & \multirow{5}{*}{861} \\
\hline & 2 & & & & & \\
\hline & 3 & & & & & \\
\hline & 4 & & & & 132 & \\
\hline & 5 & & 229 & & & \\
\hline \multirow{5}{*}{5} & 1 & & & & & \multirow{5}{*}{565} \\
\hline & 2 & 145 & & 145 & & \\
\hline & 3 & & 110 & & & \\
\hline & 4 & & & & & \\
\hline & 5 & & & & 165 & \\
\hline
\end{tabular}

Table 7: Job rotation schedule. 


\section{Ergonomics International Journal}

\section{Conclusion}

This study aims to provide an optimal job rotation strategy that maximizes production quantity and minimizes mental and physical fatique. In this context a nonlinear zero-one integer programming model is established. The proposed model is an original approach according to the studies in the literature. Forwhy, this model includes mental and physical exposure level of workers for each working period. In addition, this model can be processed different ergonomic conditions and different job rotation strategies can be obtain.

\section{References}

1. Seçkiner SU, Kurt M (2008) Ant colony optimization for the job rotation scheduling problem. Applied Mathematics and Computation 201(1): 149-160.

2. Aryanezhad MB, Kheirkhah AS, Deljoo V, Mirzapour Al-e-hashem (2009) Designing safe job rotation schedules based upon workers' skills. The International Journal of Advanced Manufacturing Technology 41(1-2): 193-199.

3. Tharmmaphornphilas W, Green B, Carnahan BJ, Norman BA (2003) Applying mathematical modeling to create job rotation schedules for minimizing occupational noise exposure. Aiha Journal 64(3): 401405.

4. Otto A, Scholl A (2013) Reducing ergonomic risks by job rotation scheduling. OR spectrum 35(3): 711-733.

5. Song J, Lee C, Lee W, Bahn S, Jung C, et al. (2016) Development of a job rotation scheduling algorithm for minimizing accumulated work load per body parts. Work 53(3): 511-521.

6. Moussavi SE, Mahdjoub M, Grunder O (2016) Reducing production cycle time by ergonomic workforce scheduling. IFAC-Papers OnLine 49(12): 419-424.

7. Yoon SY, Ko J, Jung MC (2016) A model for developing job rotation schedules that eliminate sequential high workloads and minimize between-worker variability in cumulative daily workloads: Application to automotive assembly lines. Applied ergonomics 55: 815.

8. Xie B, ve Salvendy G (2000) Review and reappraisal of modeling and predicting mental workload in single and multi-task environments. Work \& Stress 14(1): 74-99.
9. Jung HS, ve Jung HS (2001) Establishment of overall workload assessment technique for various tasks and workplaces. International Journal of Industrial Ergonomics 28(6): 341-353.

10. Dağdeviren M (2005) Employee of the Determination of Total Work Load Level Oriented Model and Application. J Fac Eng Arch Gazi Univ 20(4): 517-525.

11. Corominas A, Pastor R, Plans J (2008) Balancing assembly line with skilled and unskilled workers. OMEGA The International Journal of Management Sciences 36(6): 1126-1132.

12. Wongwien T, ve Nanthavanij S (2012) Ergonomic Workforce Scheduling for Noisy Workstations with Single or Multiple Workers per Workstation. International Journal of the Computer, the Internet and Management 20(3): 34-39.

13. Kara Y (2014) An integrated model to incorporate ergonomics and resource restrictions into assembly line balancing. International Journal of Computer Integrated Manufacturing 27(11): 997-1007.

14. Akyol SD, Baykasoğlu A (2016) ErgoALWABP: a multiple-rule based constructive randomized search algorithm for solving assembly line worker assignment and balancing problem under ergonomic risk factors. Journal of Intelligent Manufacturing, pp: 1-12.

15. Otto A, Battaïa $O$ (2017) Reducing physical ergonomic risks at assembly lines by line balancingand job rotation: A survey. Computers and Industrial Engineering 111: 467-480.

16. Otto A, Boysen N, Scholl A, Walter R (2017) Ergonomic workplace design in the fast pick area. OR Spectrum 39(4): 945-975.

17. Comper MLC, Dennerlein JT, Evangelista GDS, Rodrigues da Silva P, Padula RS (2017) Effectiveness of job rotation for preventing work-related musculoskeletal diseases: a cluster randomised controlled trial. Occup Environ Med 74(8): 545-552.

18. Wongwien T, Nanthavanij S (2017) Multiobjective Ergonomic Workforce Scheduling Under Complex Worker And Task Constraints. International Journal of Industrial Engineering: Theory, Applications and Practice 24 (3).

19. Dolgui A, Kovalev S, Kovalyovc MY, Malyutina S, ve Soukhal A (2018) Optimal workforce assignment to 


\section{Ergonomics International Journal}

operations of a paced assembly line. European Journal of Operational Research 264(1): 200-211.

20. Finia AAF, Akbarnezhad A, Rashidi TH, ve Waller ST (2018) Enhancing the safety of construction crew by accounting for brain resource requirements of activities in job assignment. Automation in Construction 88: 31-43.

21. Karhu O, Kansi P, Kuorinka I (1977) Correcting working postures in industry: a practical method for analysis. Applied ergonomics 8(4): 199-201.

22. Mattila M, Karwowski W, Vilkki M (1993) Analysis of working postures in hammering tasks on building construction sites using the computerized OWAS method. Applied Ergonomics 24(6): 405-412.

23. Pinzke S, Kopp L (2001) Marker-less systems for tracking working postures-results from two experiments. Applied Ergonomics 32(5): 461-471.

24. Saurin TA, de Macedo Guimarães LB (2008) Ergonomic assessment of suspended scaffolds. International journal of industrial ergonomics 38(2): 238-246.

25. Hoy J, Mubarak N, Nelson S, De Landas MS, Magnusson M, et al. (2005) Whole body vibration and posture as risk factors for low back pain among forklift truck drivers. Journal of Sound and Vibration 284(3): 933-946.

26. Gilkey DP, Keefe TJ, Bigelow PL, Herron RE, Duvall K, et al. (2007) Low back pain among residential carpenters: ergonomic evaluation using OWAS and 2D compression estimation. International Journal of Occupational Safety and Ergonomics 13(3): 305-321.

27. Roja Z, Kalkis V, Vain A, Kalkis H, Eglite M (2006) Assessment of skeletal muscle fatigue of road maintenance workers based on heart rate monitoring and myotonometry. Journal of Occupational Medicine and Toxicology 1(1): 1-20.
28. Brandl C, Mertens A, Schlick CM (2017) Effect of sampling interval on the reliability of ergonomic analysis using the Ovako working posture analysing system (OWAS). International Journal of Industrial Ergonomics 57: 68-73.

29. Zheng B, Jiang X, Tien G, Meneghetti A, Panton ON, et al. (2012) Workload assessment of surgeons: correlation between NASA TLX and blinks. Surgical endoscopy 26(10): 2746-2750.

30. Mazur LM, Mosaly PR, Hoyle LM, Jones EL, Marks LB (2013) Subjective and objective quantification of physician's workload and performance during radiation therapy planning tasks. Practical Radiation Oncology 3(4): e171-e177.

31. Colligan L, Potts HW, Finn CT, Sinkin RA (2015) Cognitive workload changes for nurses transitioning from a legacy system with paper documentation to a commercial electronic health record. International journal of medical informatics 84(7): 469-476.

32. Hakenes H, Katolnik S (2017) On the incentive effects of job rotation. European Economic Review 98(1): 424-441.

33. Hochdörffer J, Hedler M, Lanza G (2018) Staff scheduling in job rotation environments considering ergonomic aspects and preservation of qualifications. Journal of Manufacturing Systems 46(1): 103-114.

34. de Bruijn I, Engels JA, van der Gulden JW (1998) A simple method to evaluate the reliability of OWAS observations. Applied Ergonomics 29(4): 28 1-283.

35. Rodriguez AC, Barrero LH (2017) Job rotation: Effects on muscular activity variability. Applied Ergonomics 60: 83-92.

36. Botti L, Mora C, Calzavara M (2017) Design of job rotation schedules managing the exposure to agerelated risk factors. IFAC Papers OnLine 50(1): 13993-13997. 